Method Using the Unisoft database of our endoscopy unit we retrospectively reviewed all colonoscopies done over a consecutive 6 months period from July to December. We analysed this data looking at colonoscopy results of those whose indication was abnormal CT scan and the CT scan results of those patients with abnormal colonoscopy. Statistical analysis was performed using Chi square and Fishers exact test on SPSS. A P- value of 0.05 was taken as significant.

Results 856 colonoscopies were performed within the study time period, of these $88(9.62 \%)$ also had CT scans performed within the same month. 46 (52\%) CT scans were performed before the colonoscopy. $33 \mathrm{CTs}$ had been reported as showing colitis and 46 as showing tumour. Of 33 with colitis on CT scan only $16(57 \%)$ had colitis confirmed on colonoscopy and 14 (48\%) were normal ( $\mathrm{P}=0.0003$ Chi square, $\mathrm{P}=0.0005$ Fishers exact test). Of 46 patients with colonic tumour reported on CT scan, 32(70\%) had tumour confirmed on colonoscopy, 12 $(26 \%)$ were normal $(\mathrm{P}=0.0034$ on chi square, $\mathrm{P}=0.0053$ Fishers exact test).While $9 \mathrm{CT}$ scans were reported as normal, on colonoscopy, 6 of these had large colonic tumour and $3 \mathrm{had}$ colitis.

Conclusion This study suggest that CT scan over diagnose colitis but more importantly may under diagnose colonic tumours.

\section{IS CT OF ABDOMEN A RELIABLE INDICATOR FOR SIGNIFICANT COLONIC PATHOLOGY?}

P Maheshwari, U Jilani, C Goulding Department of Gastroenterology Midwest Regional Hoospital Limerick, Ireland

10.1136/gutjnl-2013-305143.102

Introduction We have noticed in our endoscopy unit that abnormality on abdominal CT is becoming a frequent indication for colonoscopy.

Aims/Background The primary aim of this retrospective study was to compare the gold standard of colonoscopy with CT findings. 